\title{
Temperature-dependent change of light dose effects on $E$. coli inactivation during simulated solar treatment of secondary effluent
}

\author{
Stefanos Giannakis ${ }^{1,2,3}$, Efthymios Darakas ${ }^{1}$, Antoni Escalas-Cañellas ${ }^{2,4}$, César Pulgarin ${ }^{3, *}$ \\ ${ }^{1}$ Laboratory of Environmental Engineering and Planning, Department of Civil Engineering, Aristotle \\ University of Thessaloniki, 54124 Thessaloniki, Greece \\ ${ }^{2}$ Laboratory of Control of Environmental Contamination, Institute of Textile Research and Industrial \\ Cooperation of Terrassa (INTEXTER), Universitat Politècnica de Catalunya, Colom 15, 08222 Terrassa, \\ Catalonia, Spain \\ ${ }^{3}$ Swiss Federal Institute of Technology, Lausanne, Institute of Chemical Sciences and Engineering, 1015 \\ Lausanne, Switzerland \\ ${ }^{4}$ Department of Chemical Engineering \& Terrassa School of Engineering, Universitat Politècnica de \\ Catalunya, Colom 1, 08222, Terrassa, Catalonia, Spain \\ *Corresponding author: César Pulgarin, Tel: +41216934720; Fax: +41216936161; Email: \\ cesar.pulgarin@epfl.ch
}

\begin{abstract}
In this study, simulation of solar disinfection of secondary effluents was performed, to assess the dose effects, as instructed by the reciprocity law. A full factorial experimental design on the operational parameters of the process was performed (time, temperature, bacterial load, light intensity) and three response variables were estimated (disinfection efficiency, regrowth after 24, and 48 hours). In the 240 disinfection experiments, an erratic behavior was observed in all responses to light exposure, attributed to the combination of both irradiation intensity and temperature during treatment. As a result, the validity of the reciprocity law between light dose and irradiation intensity is challenged. The majority of the cases failed to comply with it, indicating the dependence on temperature conditions, as well as the applied intensity. Dose affected the bacterial regrowth potential after 24 and $48 \mathrm{~h}$ in a more conventional way. It appears that in order to attain a valid projection of the outcome of solar disinfection in secondary effluent, intensity and dose are not the only parameters to be considered, with temperature also having to be taken under consideration.
\end{abstract}

Keywords: Dose vs. Intensity, E. coli, solar disinfection, regrowth, reciprocity law 


\section{INTRODUCTION}

In the majority of medical and biological applications, a consensus existed on the response of light dose, the so-called reciprocity law. Its formulation is stating that the total dose applied to a system will cause the same effects, independently of light intensity and exposure time (Zetterberg, 1964). Like every rule, this law has been proven false in a number of applications (Martin et al., 2003), mostly because of the irradiation fluxes used in the experiments; either very high or very low intensities can cause deviations from the expected behavior. A major application of photochemistry/photobiology, which has been extensively studied and recently reviewed (McGuigan et al., 2012) is the solar disinfection of water. This practice has drawn interest among other disinfection methods in developing countries, because of its simplicity and high acceptance rates (Ubomba-Jaswa et al., 2009; McGuigan et al., 2012). Following its introduction, more sophisticated aspects were gradually studied, such as the responses of different microorganisms and solar light delivery methods (continuous-intermittent) (Rincon and Pulgarin, 2003; Sichel et al, 2007).

Since it is natural to expect abnormalities in different species and irradiation patterns around the world, a need for experiment standarization was developed. It was soon discovered that dose can mask the reality or provide a false image on the conditions of microorganisms after irradiation. The reciprocity law in solar disinfection (SODIS) could provide an answer to that problem. Rincon and Pulgarin (2004a) stated that for the same dose, the high irradiation/low time combination provided better results for solar treatment of water, indicating a non-linear dependence between light intensity and deactivation of bacteria. Sichel et al. (2007) found that increasing the dose did not significantly improve disinfection in fungi, if the intensity was kept constant, while Bosshard et al. (2009) and Berney et al. (2006) directly challenged reciprocity law in SODIS; Bosshard et al. (2009) found some deviations of Sh. flexneri and S. typhimurium from this law, while Berney et al. (2006) verified the law for E. coli in temperatures between 40$52^{\circ} \mathrm{C}$. Peak and Peak (1982) verified the law in irradiance values only above $750 \mathrm{~W} / \mathrm{m}^{2}$. Furthermore, a notion of the post-irradiation regrowth was present in some of the previous works, as well, searching for the necessary dose (Ubomba-Jaswa et al., 2009; McGuigan et al., 2012) or exposure time, according to the respective irradiation intensities (Rincon and Pulgarin, 2004b).

To our knowledge, so far there has not been an analysis on the reciprocity law in solar wastewater treatment. Although some works evaluated the photo-inactivation potential in real 
wastewater (Maïga et al., 2009; Igoud et al., 2014), the phenomena involved are very complex and assumptions concerning the tested parameters need to be made. Here, the reciprocity law is tested in disinfection of simulated secondary effluent, a different matrix, which supports bacterial growth, rather than their plain survival (Marugan et al., 2010). We assume that the turbidity levels required for disinfection are achieved (NTU<1) (Safari et al., 2013), (theoretically) in applied pre-treatment of municipal wastewater treatment, so light action mode is not disrupted and the reported associated problems are neglected (Haider et al., 2014).

In our work, a multilevel, full factorial experimental design was applied to estimate how a set of parameters (treatment time, temperature, initial bacterial concentration and irradiation intensity) lead to deviation from reciprocity in both disinfection efficiency and subsequent regrowth. Short term (24h) and long term (48h) effects were studied.

\section{MATERIALS AND METHODS}

2.1. Synthetic secondary effluent preparation: microbial methods and wastewater composition.

The E. coli strain used was supplied by "Deutsche Sammlung von Mikroorganismen und Zellkulturen”. The bacterial preparation, have been described analytically elsewhere (Giannakis et al., 2013), as instructed by OECD, (2001). The composition of wastewater was $160 \mathrm{mg} / \mathrm{L}$ peptone, $110 \mathrm{mg} / \mathrm{L}$ meat extract, $30 \mathrm{mg} / \mathrm{L}$ urea, $28 \mathrm{mg} / \mathrm{L} \mathrm{K}_{2} \mathrm{HPO}_{4}, 7 \mathrm{mg} / \mathrm{L} \mathrm{NaCl}, 4 \mathrm{mg} / \mathrm{L}$ $\mathrm{CaCl}_{2} \cdot 2 \mathrm{H}_{2} \mathrm{O}$ and $2 \mathrm{mg} / \mathrm{L} \mathrm{MgSO}{ }_{4} \cdot 7 \mathrm{H}_{2} \mathrm{O}$, with $250 \mathrm{mg} / \mathrm{L}$ initial COD and turbidity around $1 \mathrm{NTU}$. Then, a 1/10 dilution of the effluent was performed, in order to simulate $90 \%$ BOD removal, a typical value in secondary treatment of municipal wastewater. Contrary to actual secondary effluent samples, this synthetic wastewater contained only small amounts of suspended solids. This preparation procedure for synthetic secondary effluent has been used in other published works (Velez-Colmenares et al., 2011; Giannakis et al, 2014a,b). Finally, bacteria were added until $10^{3}$ to $10^{6} \mathrm{CFU} / \mathrm{mL}$ were achieved, as instructed by the experimental design.

2.2. Experimental details: light source, bacterial enumeration and design of experiments.

Light was provided by a Suntest solar simulator, emitting $0.5 \%$ of photons in $290-300 \mathrm{~nm}$ range (UVC cut-off at $290 \mathrm{~nm}$ ), 7\% among 300 and $400 \mathrm{~nm}$ and follows the solar spectrum above that value until IR range (IR was cut-off by filtering). The batch reactors were glass, double-wall 
cylindrical reactors (height: $9 \mathrm{~cm}$, outer diameter $7.5 \mathrm{~cm}$, inner diameter $6.5 \mathrm{~cm}$, effective exposed surface $20.41 \mathrm{~cm}^{2}$ ), which were temperature controlled by a thermostat, as presented in Figure 1.

Experiments (and sampling) were done under mild stirring, while sampling was performed in hourly intervals. At each time point, $2.0 \mathrm{~mL}$ were drawn and pour-plated in PCA agar for the determination of the viable bacterial count. Diluted aliquots were done, when necessary, to achieve measurable counts on the Petri dishes. An hourly-drawn sample was kept in sterile plastic flasks in the dark, at room temperature $\left(\sim 25^{\circ} \mathrm{C}\right)$, for post-irradiation measurements of survival/regrowth after 24 and $48 \mathrm{~h}$. Experiments were performed twice, while sampling (and afterwards, plating) was done in duplicates, from 2-3 consequent dilutions.

Table 1 summarizes the design of experiments (DOE) employed in this study. Experiments were performed in three discreet intensity levels, with different initial population and controlled temperature. The choice of irradiation values represent the range of intensities reaching the earth's crust and temperature values correspond to temperatures reached in ponds around the Equator and/or in technical applications (Giannakis et al. 2014a). Finally, the runs with null intensity were not used in dose calculations, as they reflect no dose impact and act as blank thermal treatment experiments.

\section{RESULTS AND DISCUSSION}

\subsection{Challenging reciprocity law in temperature-controlled disinfection experiments}

An extensive analysis of the disinfection kinetics and the regrowth potential of the photo-treated secondary effluent was published before by the authors (Giannakis et al., 2014a; 2014b). In summary, reverse results were observed for the process efficiency, when the DOE was analyzed; for the same dose, efficiency dropped when treatment temperature was between $20-40^{\circ} \mathrm{C}$ and increased for temperatures between $50-60^{\circ} \mathrm{C}$. Literature suggests an existing synergy between irradiation and temperature at this range in drinking water (Wegelin et al., 1994; McGuigan et al., 1998); the same tendency was found there as well. Plus, there is a growth potential, which is increasing, when temperatures were near the peak growth rate for mesophiles, around $35-39^{\circ} \mathrm{C}$ (Fotadar et al., 2005); that would explain the drop in efficiency. The same, reverse effects are 
observed for bacteria stored both short and long term, where the same dose resulted in higher bacterial numbers when temperature was increased from 20 to $40^{\circ} \mathrm{C}$, and lower ones, for temperatures elevating from 50 to $60^{\circ} \mathrm{C}$. Of course, higher inactivation rates occurred in the highest temperatures and higher doses. Also, low doses led to usually higher rates. This was in accordance with Rincon and Pulgarin (2004a), who support that dose is an inappropriate standard for comparison, if irradiation intensity is not taken under consideration.

However, when examining the disinfection results in more depth, the importance of considering temperature as a key factor in intensity and dose studies is explained. Figure 2 (a-h) illustrates the disinfection curves for each initial temperature range and each temperature level, as a function of dose. A stepwise increase of temperature, for all initial population levels, is further examined.

At $20^{\circ} \mathrm{C}$ treatment temperature, the same dose is more efficient if it derives from lower irradiation intensities (continuous vs. dashed line). For treatment temperatures around $30^{\circ} \mathrm{C}$ the same tendency in the experiments is observed (exception: $30^{\circ} \mathrm{C}-10^{6} \mathrm{CFU} / \mathrm{mL}$, probably a statistical error, 1 case out of 240 or $0.42 \%$ deviation). However, at $40^{\circ} \mathrm{C}$ the disinfection kinetics started to change. There is faster initial inactivation rate for low intensities, but as dose increases, for the same total dose, higher intensities are more effective; for a given dose lower intensities cannot cope with the growth observed in the matrix. At $50^{\circ} \mathrm{C}$ treatment temperature, it was concluded that higher intensities, for the same dose, seem to inactivate bacteria faster than the respective dose, resulting from lower intensities. At $60^{\circ} \mathrm{C}$ it is not possible to fully evaluate the reciprocity law, because there is only two points per curve, both yielding total inactivation. The exact dose required for total inactivation cannot be calculated, because the sampling time (30 or $60 \mathrm{~min}$ ) resulted too long to notice the real difference in an almost purely thermal-driven system.

Normally, the reciprocity law should be applicable, according to Peak and Peak (1982), because all our intensities were higher than $750 \mathrm{~W} / \mathrm{m}^{2}$. Bosshard et al. (2009) validated reciprocity law for less than $750 \mathrm{~W} / \mathrm{m}^{2}\left(400 \mathrm{~W} / \mathrm{m}^{2}\right)$, but for Shigella flexneri and Salmonella typhimurium. Also, Berney et al. (2006), working in similar high-temperature range (in mineral water), did validate the reciprocity law. However, this study has shown very different results, with significant deviations from reciprocity at low and high temperatures, but in opposite directions. In the presented experiments, temperature can lead to important deviations from the reciprocity law, caused by the growth patterns at each temperature level. 


\subsection{Disinfection and regrowth dependence on light dose}

In Figure 3 (a-f) the effects on disinfection and regrowth are presented, according to the dose and the respective irradiation intensity. However, having noticed this dual, temperature-dependent behavior in disinfection and regrowth, results are presented per temperature range (Figures 3a, 3c and $3 \mathrm{~g}$ for $20-40^{\circ} \mathrm{C}$ and Figures $3 \mathrm{~b}, 3 \mathrm{~d}$ and $3 \mathrm{~h}$ for $50-60^{\circ} \mathrm{C}$ ). In fact, the tendencies observed are worth analyzing one step further: for low treatment temperatures (Figure 3a) dose has different effect when it derives from high or low irradiation intensity. It was noted that for the same dose, generally lower intensities were more efficient. However, it is observed here that in very high doses, this difference is partly mitigated. Figure $3 b$ demonstrates the changing effect temperature has in efficiency. Doses which were achieved from low irradiation intensities, do not differ significantly from the ones acquired from high intensities, but are clearly more efficient (differences along $\mathrm{X}$ axis).

Concerning the regrowth of the microorganisms, the results are more significant; in Figure 3c the effect intensity has on short-term storage is presented; low dose-high intensity experiments seem to result in higher bacterial numbers than low dose-low intensity experiments, for treatment temperatures between $20-40^{\circ} \mathrm{C}$. This is consistent with the disinfection trend observed at low temperature. Moreover, these results partly agree with previous findings, where UVA-irradiated cells were not able to regrow (Oates et al., 2003; Bosshard et al., 2009 and more), because the inflicted dose was non-lethal. However, no regrowth was observed on fully inactivated samples. In higher temperatures (above $40^{\circ} \mathrm{C}$ ), thermal action seemed to mitigate this effect, leading to much lower bacterial survival rates, which decrease normally when dose increases and are also slightly higher for low intensities. As far as long term storage (48-h) is concerned, consistent behavior in the two temperature ranges was demonstrated: the same dose was more effective in suppressing bacterial growth when it derived from higher intensity levels. However, when samples were treated at low temperatures, the regrowth potential was considerably higher.

\section{CONCLUSIONS}

In this study, the validity of the reciprocity law was tested and was actually verified for very few cases, such as high temperature experiments. The effect of high and low irradiation intensities should be evaluated separately depending on the underlying temperature range. In our work, disinfection kinetics revealed different inactivation rates for the same dose, being higher for low 
intensities at low temperatures (except for $40^{\circ} \mathrm{C}$ ) and lower for higher intensities at higher temperatures. Bacterial growth has interfered in the normal evolution of the process $\left(20-40^{\circ} \mathrm{C}\right)$. For regrowth, temperature appears to be the critical factor in wastewater, resulting in high rates at low temperatures (although increasing towards $30-40^{\circ} \mathrm{C}$ ) and low ratios in samples treated in warmer water. Short term storage could be dangerous if treated for a short time at high intensities, while long term one is more susceptible to present regrown numbers at low doses deriving from low intensities.

These results can significantly influence natural solar treatment methods of wastewater, because they indicate the feasibility of applying such a method, without the need to achieve high temperatures. Even at temperatures as low as $20^{\circ} \mathrm{C}$, low intensities could result in total disinfection, if the exposure is prolonged. Therefore, reciprocity law is a rather simplified image of the real bacterial response to photo-treatment and our study indicates that there are more factors affecting this generalized rule. A more detailed study on the role of intensity, at critically low temperatures, currently in progress in our Group, will try to further address this abnormality.

\section{ACKNOWLEDGEMENTS}

The authors wish to thank, in order of acquisition, the Mediterranean Office for Youth Program (MOY, call 2011-2014), by means of which Mr. Stefanos Giannakis has received a PhD mobility grant (MOY grant No2010/044/01) in the joint Environmental Engineering Doctoral Program. Also would wish to thank the Swiss Government for the Swiss Government Excellence Scholarship, by means of which Mr. Stefanos Giannakis has received a Research Visit fellowship (No. 2012.0499). 


\section{REFERENCES}

M. Berney, H.U. Weilenmann, A. Simonetti, T. Egli, Efficacy of solar disinfection of Escherichia coli, Shigella flexneri, Salmonella Typhimurium and Vibrio cholerae, Journal of applied microbiology, 101 (2006) 828-836.

F. Bosshard, M. Berney, M. Scheifele, H.U. Weilenmann, T. Egli, Solar disinfection (SODIS) and subsequent dark storage of Salmonella typhimurium and Shigella flexneri monitored by flow cytometry, Microbiology, 155 (2009) 1310-1317.

U. Fotadar, P. Zaveloff, L. Terracio, Growth of Escherichia coli at elevated temperatures, Journal of basic microbiology, 45 (2005) 403-404.

S. Giannakis, A.I. Merino Gamo, E. Darakas, A. Escalas-Cañellas, C. Pulgarin, Impact of different light intermittence regimes on bacteria during simulated solar treatment of secondary effluent: Implications of the inserted dark periods, Solar Energy, 98, Part C (2013) 572-581.

S. Giannakis, E. Darakas, A. Escalas-Cañellas, C. Pulgarin, The antagonistic and synergistic effects of temperature during solar disinfection of synthetic secondary effluent, Journal of Photochemistry and Photobiology A: Chemistry, 280 (2014a) 14-26.

S. Giannakis, E. Darakas, A. Escalas-Cañellas, C. Pulgarin, Elucidating bacterial regrowth: Effect of disinfection conditions in dark storage of solar treated secondary effluent, Journal of Photochemistry and Photobiology A: Chemistry, 290 (2014b) 43-53.

H. Haider, W. Ali, S. Haydar, S. Tesfamariam, R. Sadiq. Modeling exposure period for solar disinfection (SODIS) under varying turbidity and cloud cover conditions. Clean Technologies and Environmental Policy, 16(5), (2014) 861-874. doi: 10.1007/s10098-013-0677-4

S. Igoud, F. Souahi, C.E. Chitour, L. Amrouche, C. Lamaa, N. Chekir, A. Chouikh. Wastewater disinfection using ultraviolet (UVA, UVC) and solar radiation. Desalination and Water Treatment, (2014) 1-7. doi: 10.1080/19443994.2014.968909

Y. Maïga, K. Denyigba, J. Wethe, A.S. Ouattara,. Sunlight inactivation of Escherichia coli in waste stabilization microcosms in a sahelian region (Ouagadougou, Burkina Faso). Journal of Photochemistry and Photobiology B: Biology, 94(2), (2009) 113-119. doi: http://dx.doi.org/10.1016/j.jphotobiol.2008.10.008 
J.W. Martin, J.W. Chin, T. Nguyen, Reciprocity law experiments in polymeric photodegradation: a critical review, Progress in Organic Coatings, 47 (2003) 292-311.

J. Marugán, R. van Grieken, C. Pablos, C. Sordo, Analogies and differences between photocatalytic oxidation of chemicals and photocatalytic inactivation of microorganisms, Water research, 44 (2010) 789-796.

K. McGuigan, T. Joyce, R. Conroy, J. Gillespie, M. Elmore-Meegan, Solar disinfection of drinking water contained in transparent plastic bottles: characterizing the bacterial inactivation process, Journal of applied microbiology, 84 (1998) 1138-1148.

K.G. McGuigan, R.M. Conroy, H.J. Mosler, M. du Preez, E. Ubomba-Jaswa, P. FernandezIbanez, Solar water disinfection (SODIS): a review from bench-top to roof-top, Journal of hazardous materials, 235-236 (2012) 29-46.

P.M. Oates, P. Shanahan, M.F. Polz, Solar disinfection (SODIS): simulation of solar radiation for global assessment and application for point-of-use water treatment in Haiti, Water research, 37 (2003) 47-54.

OECD Guidelines for Testing of Chemicals, Simulation Test-Aerobic Sewage Treatment 303A, 2001

J. Peak, M. Peak, Lethality in repair-proficient Escherichia coli after $365 \mathrm{~nm}$ ultraviolet light irradiation is dependent on fluence rate, Photochemistry and photobiology, 36 (1982) 103-105.

A.-G. Rincon, C. Pulgarin, Photocatalytical inactivation of E. coli: effect of (continuousintermittent) light intensity and of (suspended-fixed) TiO2 concentration, Applied Catalysis B: Environmental, 44 (2003) 263-284.

A.-G. Rincon, C. Pulgarin, Field solar E. coli inactivation in the absence and presence of TiO2: is UV solar dose an appropriate parameter for standardization of water solar disinfection?, Solar Energy, 77 (2004a) 635-648.

A.-G. Rincon, C. Pulgarin, Bactericidal action of illuminated TiO2 on pure Escherichia coli and natural bacterial consortia: post-irradiation events in the dark and assessment of the effective disinfection time, Applied Catalysis B: Environmental, 49 (2004b) 99-112.

G. Safari, K. Yetilmezsoy, A. Mahvi, M. Zarrabi. Post-treatment of secondary wastewater treatment plant effluent using a two-stage fluidized bed bioreactor system. Journal of Environmental Health Science and Engineering, 11(1) (2013), 10. 
C. Sichel, J. Tello, M. de Cara, P. Fernández-Ibáñez, Effect of UV solar intensity and dose on the photocatalytic disinfection of bacteria and fungi, Catalysis Today, 129 (2007) 152-160.

E. Ubomba-Jaswa, C. Navntoft, M.I. Polo-López, P. Fernandez-Ibáñez, K.G. McGuigan, Solar disinfection of drinking water (SODIS): an investigation of the effect of UV-A dose on inactivation efficiency, Photochemical \& Photobiological Sciences, 8 (2009) 587-595.

Velez-Colmenares, J.J., Acevedo, A., Nebot, E., 2011. Effect of recirculation and initial concentration of microorganisms on the disinfection kinetics of Escherichia coli. Desalination, 280, 20-26

M. Wegelin, S. Canonica, K. Mechsner, T. Fleischmann, F. Pesaro, A. Metzler, Solar water disinfection: scope of the process and analysis of radiation experiments, Aqua, 43 (1994) 154169.

G. Zetterberg, Mutagenic effects of ultraviolet and visible light. In Photophysiology, ed. Giese, A.G. (1964) New York: Academic Press 


\section{List of Tables}

Table 1: Summary of the DOE

\begin{tabular}{ccc}
\hline Parameters & Levels & Units \\
\hline Time & $\mathbf{4}$ & $\mathrm{h}$ \\
Initial Population & $(1,2,3,4)$ & $\mathrm{CFU} / \mathrm{mL}$ \\
Temperature & $\left(10^{3}, 10^{4}, 10^{5}, 10^{6}\right)$ & \\
Light Intensity & $\mathbf{5}$ & ${ }^{\circ} \mathrm{C}$ \\
\hline
\end{tabular}

\section{List of Figures}

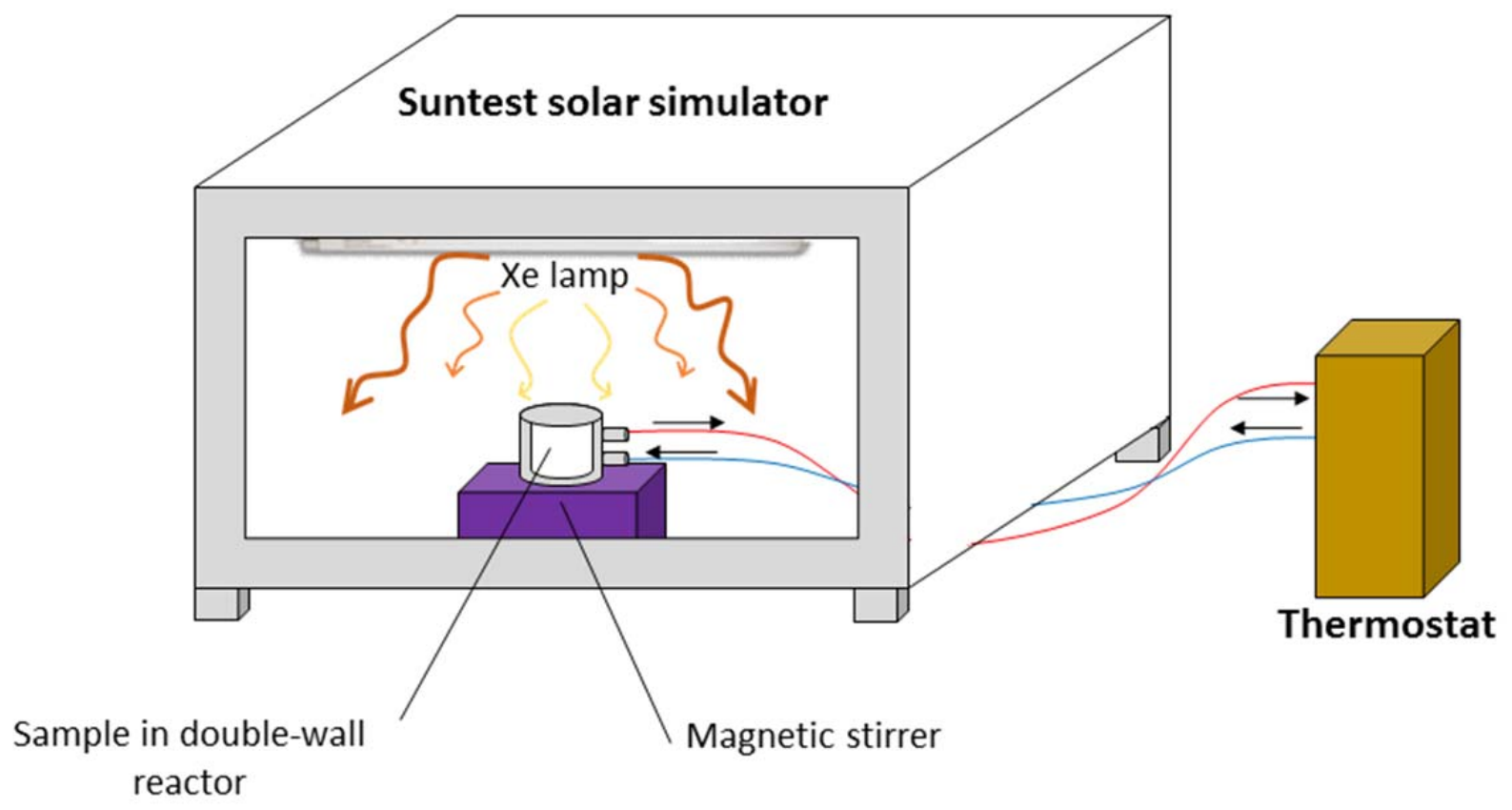

Figure 1 - Schematic representation of the experimental set-up 

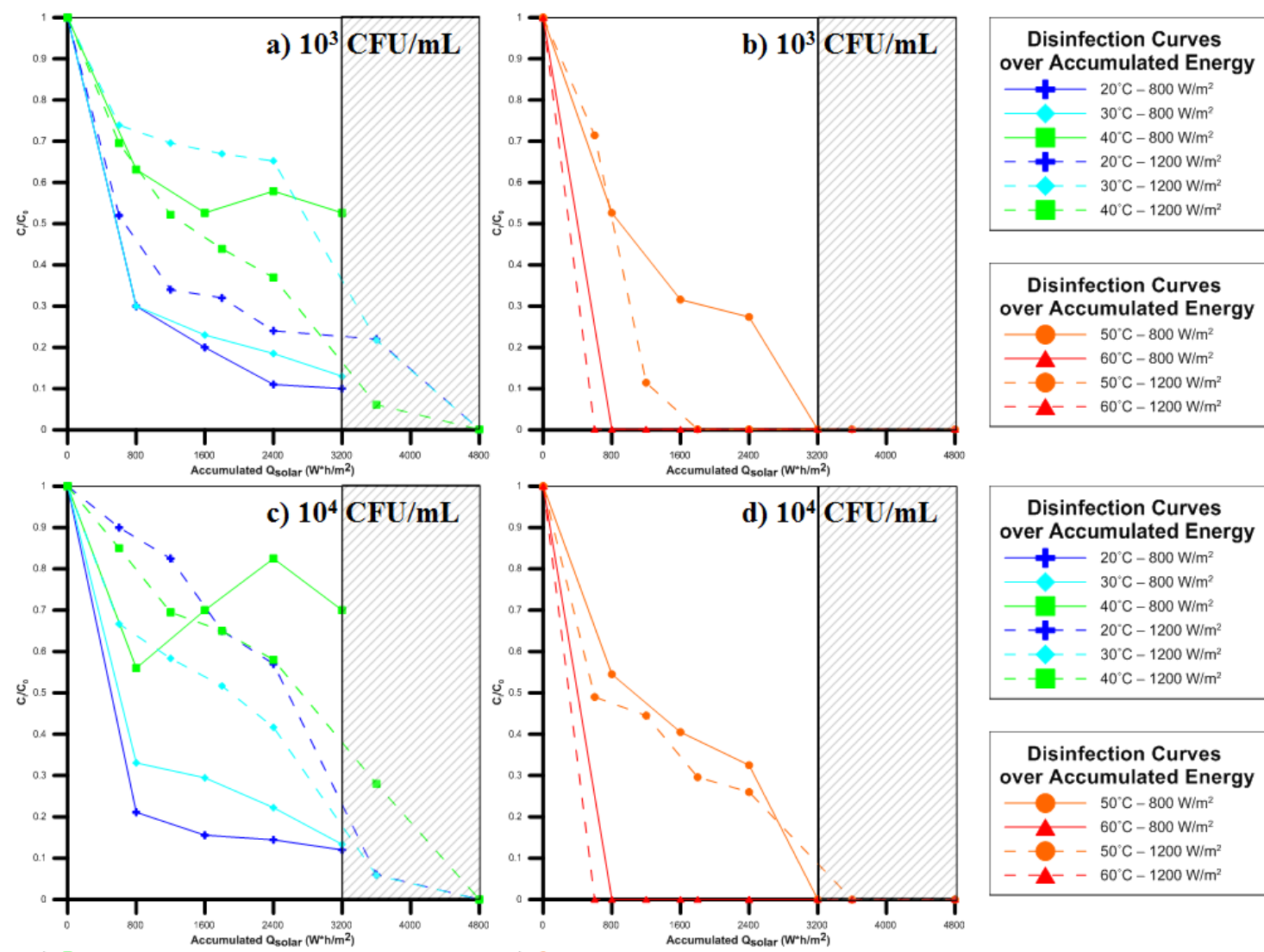

Disinfection Curves over Accumulated Energy

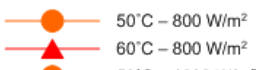

- $50^{\circ} \mathrm{C}-1200 \mathrm{~W} / \mathrm{m}^{2}$ $-60^{\circ} \mathrm{C}-1200 \mathrm{~W} / \mathrm{m}^{2}$
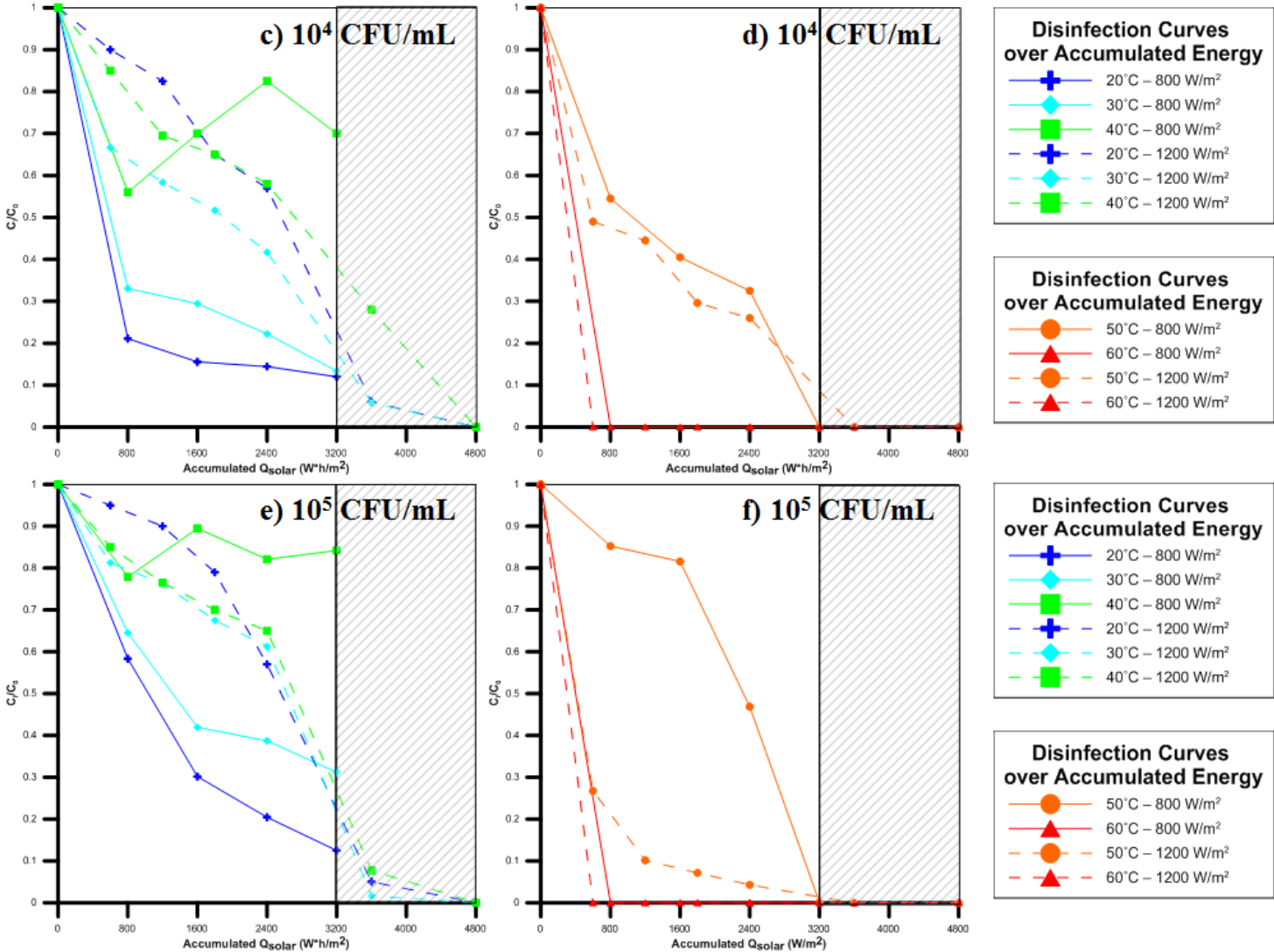

Disinfection Curves over Accumulated Energy $50^{\circ} \mathrm{C}-800 \mathrm{~W} / \mathrm{m}^{2}$ - $60^{\circ} \mathrm{C}-800 \mathrm{~W} / \mathrm{m}^{2}$ - $50^{\circ} \mathrm{C}-1200 \mathrm{~W} / \mathrm{m}^{2}$ $-60^{\circ} \mathrm{C}-1200 \mathrm{~W} / \mathrm{m}^{2}$
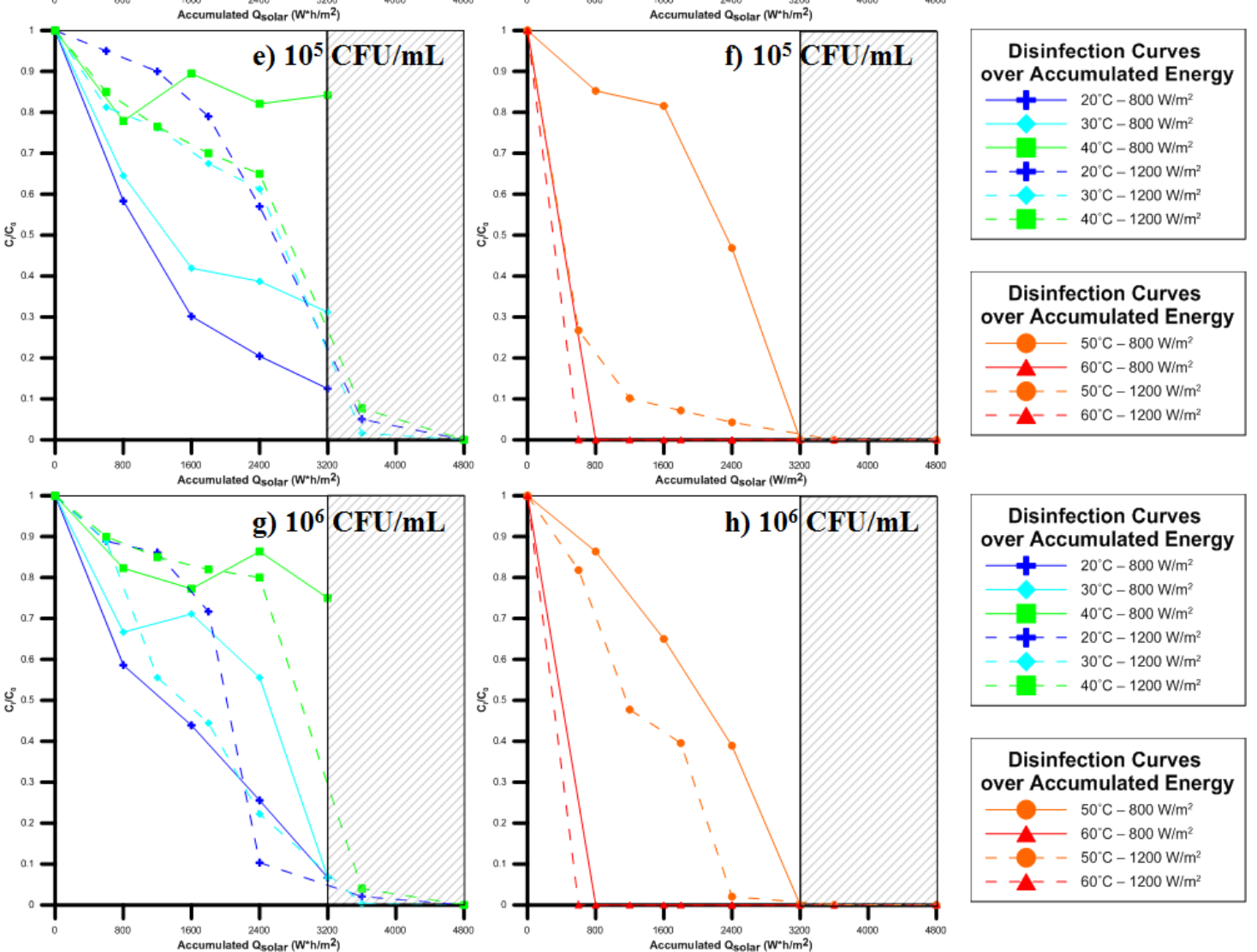

Disinfection Curves over Accumulated Energy $50^{\circ} \mathrm{C}-800 \mathrm{~W} / \mathrm{m}^{2}$ $60^{\circ} \mathrm{C}-800 \mathrm{~W} / \mathrm{m}^{2}$ $-\quad 60^{\circ} \mathrm{C}-1200 \mathrm{~W} / \mathrm{m}^{2}$

Figure 2 - Overview of the disinfection experiments. On the left side: experiments with $20 \leq T \leq 40^{\circ} \mathrm{C}$ and $40<\mathrm{T} \leq 60^{\circ} \mathrm{C}$ on the right. (a) and (b): $10^{3} \mathrm{CFU} / \mathrm{mL}$. (c) and (d): $10^{4} \mathrm{CFU} / \mathrm{mL}$. (e) and (f): $10^{5}$ CFU/mL. (g) and (h): $10^{6} \mathrm{CFU} / \mathrm{mL}$. 


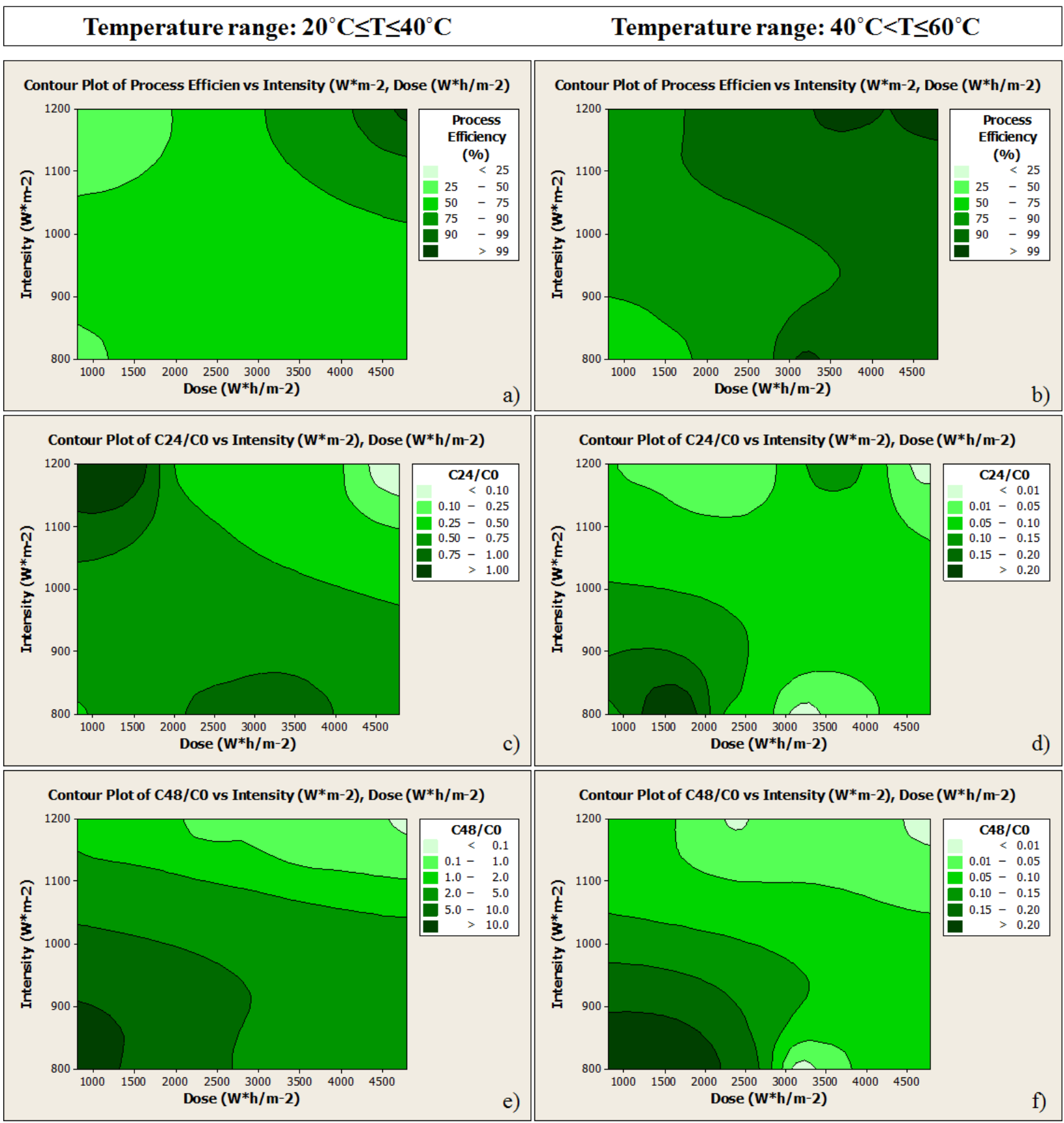

Figure 3 - Overview of the experimental results under the prism of dose/intensity. (a) Contour plot of the process efficiency vs. intensity and dose, for $20 \leq \mathrm{T} \leq 40^{\circ} \mathrm{C}$. (b) Contour plot of the process efficiency vs. intensity and dose, for $40<\mathrm{T} \leq 60^{\circ} \mathrm{C}$. (c) Contour plot of the regrowth after $24 \mathrm{~h}$ vs. intensity and dose, for $20 \leq \mathrm{T} \leq 40^{\circ} \mathrm{C}$. (d) Contour plot of the regrowth after $24 \mathrm{~h}$ vs. intensity and dose, for $40<\mathrm{T} \leq 60^{\circ} \mathrm{C}$. (e) Contour plot of the regrowth after $48 \mathrm{~h}$ vs. intensity and dose, for $20 \leq \mathrm{T} \leq 40^{\circ} \mathrm{C}$. (f) Contour plot of the regrowth after $48 \mathrm{~h}$ vs. intensity and dose, for $40<\mathrm{T} \leq 60^{\circ} \mathrm{C}$. 